\title{
Ecology of a North Sea pockmark with an active methane seep
}

\author{
P. R. Dando ${ }^{1}$, M. C. Austen ${ }^{2}$, R. A. Burke $\mathrm{Jr}^{3}$, M. A. Kendall ${ }^{2}$, M. C. Kennicutt $\mathrm{II}^{3}$, \\ A. G. Judd ${ }^{4}$, D. C. Moore ${ }^{5}$, S. C. M. O'Hara' ${ }^{1,2}$, R. Schmaljohann ${ }^{6}$, A. J. Southward ${ }^{1}$ \\ ${ }^{1}$ Marine Biological Association of the UK, Citadel Hill, Plymouth PL1 2PB, United Kingdom \\ ${ }^{2}$ Plymouth Marine Laboratory, Prospect Place, Plymouth PL1 3DH, United Kingdom \\ ${ }^{3}$ Geochemical and Environmental Research Group, Texas A \& M University, College Station, Texas 77840, USA \\ ${ }^{4}$ School of Environmental Technology, Sunderland Polytechnic, Sunderland SR2 7BW United Kingdom \\ ${ }^{5}$ Marine Laboratory, DAFS, PO Box 101, Victoria Road, Aberdeen AB9 8 DB, United Kingdom \\ ${ }^{6}$ Institut für Meereskunde an der Universität Kiel, Düsternbrooker Weg 20, D-2300 Kiel, Germany
}

\begin{abstract}
At a large North Sea pockmark, with active methane seeps, surface sediments were found to have higher insoluble sulphide concentrations than sediments from the surrounding area. The fauna of the pockmark was characterized by 2 species which have not previously been reported from the Fladen Ground in the northern North Sea. These species were a bivalve, Thyasira sarsi (which is known to contain endosymbiotic sulphur-oxidising bacteria) and a mouthless and gutless nematode, Astomonema sp., which also contains endosymbiotic bacteria. The nematode was the dominant meiofauna species in the pockmark sediments. Both macro-infauna and total nematodes were in low abundance in samples taken from the base of the pockmark. Sediment samples from the pockmark contained numerous otoliths, implying that substantial winnowing of the sediment had taken place. This was supported by studies on the sulphide concentrations in the sediment which showed multiple layering of the sediments on the sides of the pockmark, suggesting displacement. The carbon isotope compositions $\left(\delta^{13} \mathrm{C}\right)$ of the tissues of benthic animals from in and around the pockmark were generally in the range -16 to $-20 \%$, indicating that little methane-derived carbon was contributing to their nutrition. $T$. sarsi had the most ${ }^{13} \mathrm{C}$-depleted tissues, -31.4 to $-35.1 \%$, confirming the nutritional dependence of this species on chemoautotrophic bacteria that utilize reduced sulphur
\end{abstract}

\section{INTRODUCTION}

Pockmarks in the northern North Sea are believed to have been formed by rapid expulsion of gas and liquid through the seabed, displacing fine-grained sediment and forming characteristic craters (Hovland \& Judd 1988). Much of the gas forming these pockmarks is believed to be methane. It has been suggested that methane seeping from pockmarks and micro-seepages in the North Sea increases local benthic production through a bacteria-based food web (Hovland \& Judd 1988, Hovland \& Thomsen 1989). This suggestion was based on video recordings of the seabed which indicated that a richer fauna was associated with pockmarks and seepage sites as compared to the surrounding areas.

Hydrocarbon-rich sediments tend to have higher sulphate reduction rates and hence high concentrations of sulphides (Ivanov et al. 1989). Invertebrates which obtain their nutrition from symbiotic sulphur-oxidising or methane-oxidising bacteria have been found at hydrocarbon seeps in the Skagerrak (Schmaljohann \& Flügel 1987, Schmaljohann et al. 1990), off California (Davis \& Spies 1980, Kennicutt et al. 1989) and on the Louisiana Continental Slope (Kennicutt et al. 1985). Stable isotope ratios of animal tissues and food sources are used to infer the form of nutrition and to indicate the presence of petroleum-derived carbon in the benthic food web (Spies et al. 1980, Paull et al. 1985, Kennicutt et al. 1989).

Pockmarks are common, up to $40 \mathrm{~km}^{-2}$, on the thick deposits in the central part of the Fladen Ground basin in the northern North Sea (Jansen 1976, Long 1986). The surface deposits are typically soft multi-layered muds containing subordinate silty and sandy horizons. These soft muds overly a stiff, dark gray, silty-clay of the Swatchway and Claypit Formations. This clay was subjected to ice-loading in the late Weichselian, result- 
ing in a discrete boundary between the stiff clay and the upper, mainly Holocene, deposits. A large pockmark with active methane seeps in UK block 15/25 was first described by Hovland \& Sommerville (1985). Boomer and side-scan sonar data indicated that in the centre of the depression $17 \mathrm{~m}$ of sediment had been removed to expose the firm clay below. The gas escaping from this pockmark has been reported to be biogenic methane, $\delta^{13} \mathrm{C}-70 \%$ (Hovland \& Irwin 1989). The closest producing oil field to the site is the Balmoral, ca $10 \mathrm{~km}$ to the south east.

The objectives of the present study were to investigate the geochemistry and biology of this pockmark and its surroundings to establish whether methane was contributing carbon to the benthic food web and whether species dependent on sulphur-oxidising bacteria were an important part of the fauna.

\section{METHODS}

The pockmark at $58^{\circ} 16.95^{\prime} \mathrm{N}, 00^{\circ} 59.20^{\prime} \mathrm{E}$ was surveyed and sampled using FRV 'Scotia' on 6 June 1989 and MV 'Resolution' on 11 to 12 July 1989. It is a shallow depression ca 600 by $300 \mathrm{~m}$ across with a maximum depth of $18.5 \mathrm{~m}$ below the surrounding sea floor, which lies at $150 \mathrm{~m}$ below sea level. The depression was located using the Pulse 8 navigation system on the 'Scotia' and by Decca Navigator on the 'Resolution'.

Sediment samples were collected with a SmithMcIntyre grab sampling $0.1 \mathrm{~m}^{2}$, a gravity corer or a multiple corer on the 'Scotia' (S1 to S11), and with a box corer (Jonasson \& Olausson 1966) sampling $0.085 \mathrm{~m}^{2}$ on the 'Resolution' (R1 to R8). The locations of the sampling sites are shown in Fig. 1: their exact position in relation to the centre of the pockmark can be judged from the water depth in which they were collected. Samples for chemical analysis were taken from subcores from the central part of the box and sliced horizontally, or directly from the box core after removal of a side panel of the liner and the sediment immediately adjacent to it. Sub-cores for gas analysis were handled in a glove bag under nitrogen, and core sections were extruded into sample jars containing sodium azide in degassed water; methane was determined by analysis of samples of the headspace gases in the jars (Dando et al. 1986). Water samples were collected in plastic NIO reversing bottles. At the pockmarks the cast of bottles was positioned within, or as close as possible to, the 'plume' seen on the echo sounder record (Fig. 3). The water was transferred through a PVC tube to sample bottles, containing sodium azide, in a glove bag under nitrogen. The $150 \mathrm{ml}$ bottles were partially filled, leaving a nitrogen headspace, and immediately sealed with PTFE-coated silicone rubber septa. After shaking for

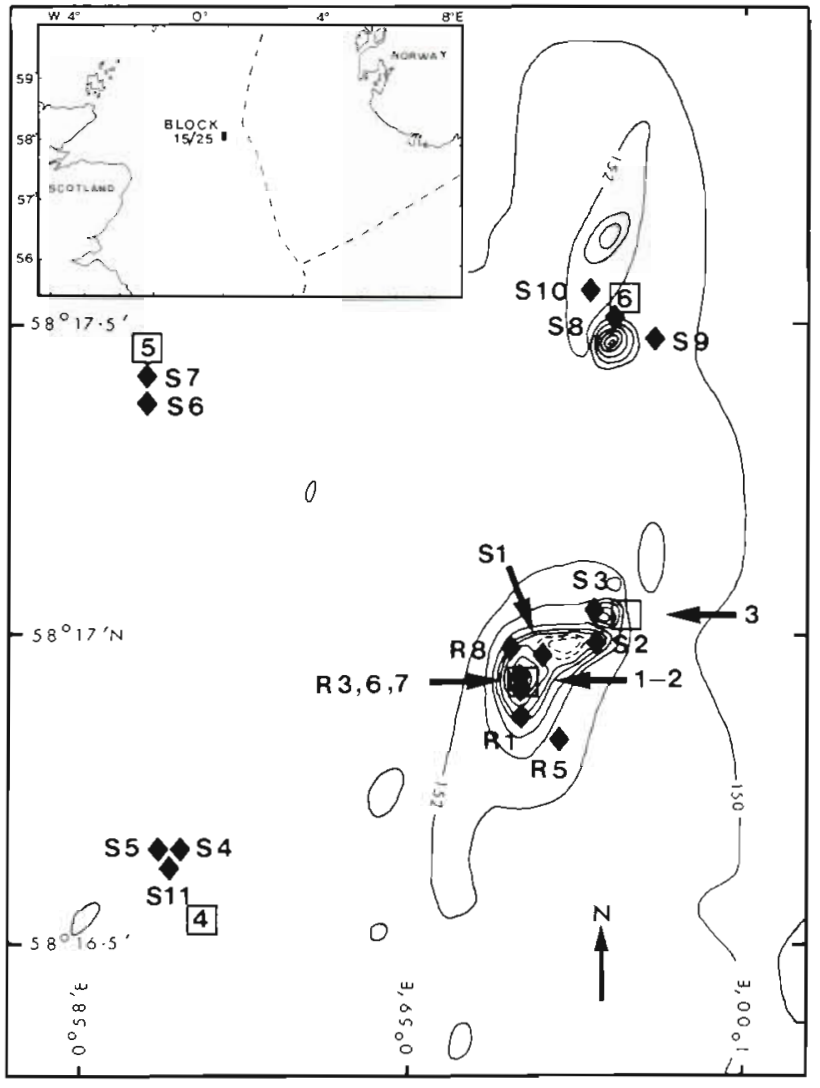

Fig. 1. Location of the pockmark studied and the positions of the sediment $(\$)$ and water samples $(\square)$ obtained. The inset shows the position of the area in the North Sea. Dotted lines indicate the boundaries between the national exclusive economic zones

$1 \mathrm{~h}$ to equilibrate the gases methane was determined in aliquots of the head space gas.

Samples $(1 \mathrm{ml})$ of sediment for reduced sulphur analysis were taken in a cut-off plastic syringe and stored under argon in $2 \% \mathrm{w} / \mathrm{v}$ cadmium chloride solution. Elemental sulphur was extracted by shaking with hexane under argon and determined by HPL.C (Lauren \& Watkinson 1985). The remaining sediment was acidified under argon with $5.5 \mathrm{M}$ hydrochloric acid; the hydrogen sulphide evolved was trapped in neutralised zinc acetate solution and measured by the technique of Cline (1969). A second hexane extraction was performed to remove elemental sulphur formed during acidification and sulphur was again determined by HPLC of aliquots of the hexane solution. Acid-volatile sulphide was calculated as the total of the sulphide in the zinc acetate trap plus the sulphur in the second hexane extraction. Chromous-reducible sulphide, largely pyrite, was determined on the residue by reduction with chromous chloride (Zhabina \& Volkov 1978), trapping the hydrogen sulphide produced in zinc acetate, and determination by the method of Cline (1969). 
Sulphate reduction rates were determined by the ${ }^{35} \mathrm{~S}$ tracer technique (Jørgensen 1978). A $4 \mathrm{ml}$ sediment sample was taken in a $5 \mathrm{ml}$ cut-off plastic syringe and the cut end was sealed with a rubber bung. Then $5 \mu$ of carrier-free ${ }^{35} \mathrm{SO}_{4}{ }^{2-}(5 \mu \mathrm{Ci})$ was injected into the sediment through the plunger seal of the syringe. The syringe was incubated in the dark in a water bath at the in situ sediment temperature, $7.5^{\circ} \mathrm{C}$, for $12 \mathrm{~h}$. After this time the sediment was transferred to a vial containing $5 \mathrm{ml}$ of $2 \%$ cadmium chloride solution under argon and shaken to stop further bacterial action. Reduced sulphur species were fractionated as above before determining the radioactivity in the fractions. Results are reported in this paper as the sum of $\mathrm{S}^{\circ}+$ acid-labile sulphide + chromous-reducible sulphide. Hexane extracts were washed 6 times with distilled water to remove any residual sulphate. Controls containing $5 \mu \mathrm{l}$ of ${ }^{35} \mathrm{SO}_{4}{ }^{2-}$ in $5 \mathrm{ml}$ of cadmium chloride were treated in a similar manner to the sediment samples. The sulphate concentration in the interstitial water was determined by HPLC using a $25 \times 0.4 \mathrm{~cm}$ column of $5 \mu \mathrm{m}$ Spherisorb ODS-1 eluted with $10 \mathrm{mM} \mathrm{NaH}_{2} \mathrm{PO}_{4}$ and $0.7 \mathrm{mM}$ tetrabutylammonium hydroxide, $\mathrm{pH}$ 6.3, at $40^{\circ} \mathrm{C}$ : a Shimadzu CDD-6 conductivity detector was used for determining the ions. The rate of sulphate reduction was calculated from the amount of ${ }^{35} \mathrm{~S}$-sulphide and -elemental sulphur formed and from the concentration and activity of the sulphate.

Methane oxidation rates were measured on $5 \mathrm{ml}$ sediment samples, suspended in $3 \mathrm{ml}$ of $0.2 \mu \mathrm{m}$ filtered seawater contained in a $20 \mathrm{ml}$ septum vial. Methane was added to the air headspace to bring the final concentration to $600 \mathrm{vpm}$. The vials were incubated in a shaking water bath at $7.5^{\circ} \mathrm{C}$. Aliquots $(100 \mu \mathrm{l})$ of the headspace gas ware analysed for methane at ca $12 \mathrm{~h}$ intervals.

Samples of carbonate cement were examined by light microscopy and selected pieces were subjected to $X$-ray micro-analysis on a JEOL $35 \mathrm{C}$ scanning microscope fitted with a Link detector and 860 analysis system. Sensivity factors were obtained using a sample of pyrite (Camborne School of Mines). Some of the cement was ground in a ball mill and used for stable isotope ratio determinations.

Sediment samples for nematode identification were taken from the centre of the box cores, using a cut-off syringe of $26 \mathrm{~mm}$ i. d., to a depth of $90 \mathrm{~mm}$. The samples were extracted according to Austen \& Warwick (1989). Numbers of Astomonema sp. (see 'Results') at different sediment depths were determined on frozen sediment samples from one core. Macrofauna was collected by washing the sediment through a $0.5 \mathrm{~mm}$ mesh sieve. Additional macrofauna samples were collected from 2 hauls of an $8 \mathrm{ft}(2.44 \mathrm{~m})$ Agassiz trawl towed through the centre of the pockmark.

Animals and tissues for carbon isotope analysis were treated with $2 \mathrm{M}$ hydrochloric acid to remove inorganic carbonate, washed in de-ionized distilled water, dried at $60^{\circ} \mathrm{C}$ and ground in a ball mill. These samples were prepared for stable isotope analysis by combustion in sealed quartz tubes at 750 to $800^{\circ} \mathrm{C}$. The resulting $\mathrm{CO}_{2}$ was cryogenically purified at $-78^{\circ} \mathrm{C}$ and analyzed with a Finnigan MAT 251 isotope ratio mass spectrometer. Results are reported relative to the Peedee Belemnite standard in the $\delta$ notation:

$$
\delta(\%)=\left[\left({ }^{13} \mathrm{C} /{ }^{12} \mathrm{C}\right)_{\text {sample }} /\left({ }^{13} \mathrm{C} /{ }^{12} \mathrm{C}\right)_{\text {standard }}-1\right] \times 1000 .
$$

\section{RESULTS}

Echo-sounding transects across the pockmark are shown in Figs $2 \& 3$. The maximum depth of the pockmark was shown to be $18.5 \mathrm{~m}$ below the surrounding plateau. Samples taken in the base of the pockmark were of stiff clay. On 4 occasions the jaws of the box corer closed but no sediment was collected, possibly due to a deposit of carbonate-cemented sand on part of the bottom. A piece of this rock was caught between the jaws of the corer on one occasion. Stable carbon
Fig. 2. Echo-sounding transect, at frequencies of 33 and $210 \mathrm{kHz}$, across the pockmark from SE to NW on 10 July 1989. W: wipeout zone, probably due to acoustic reflection and scattering by gas higher in the water column

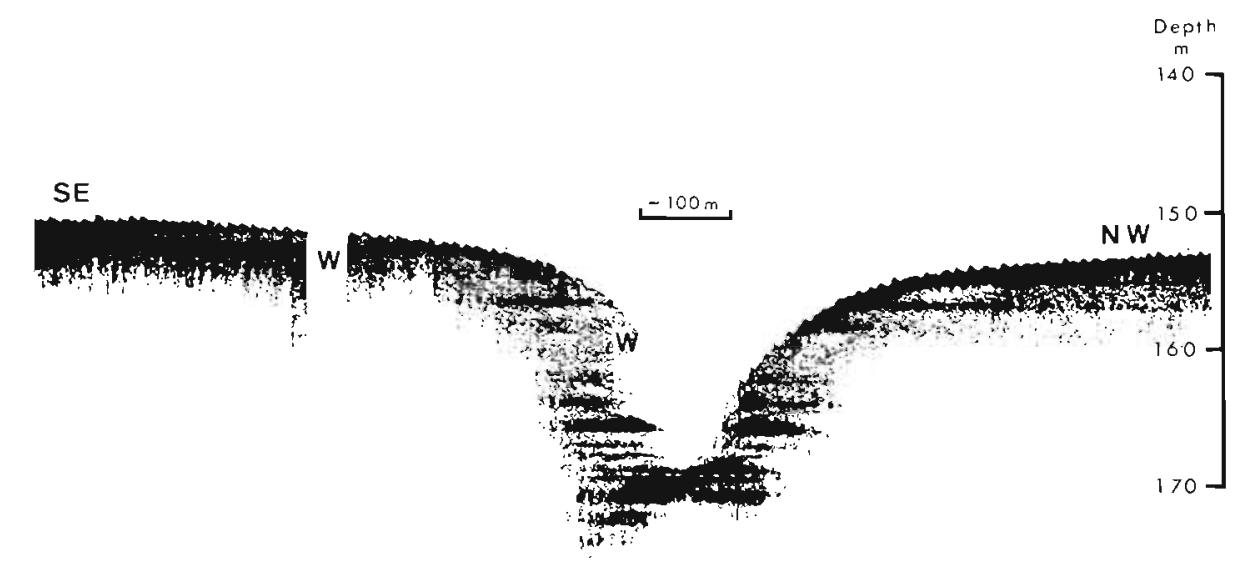




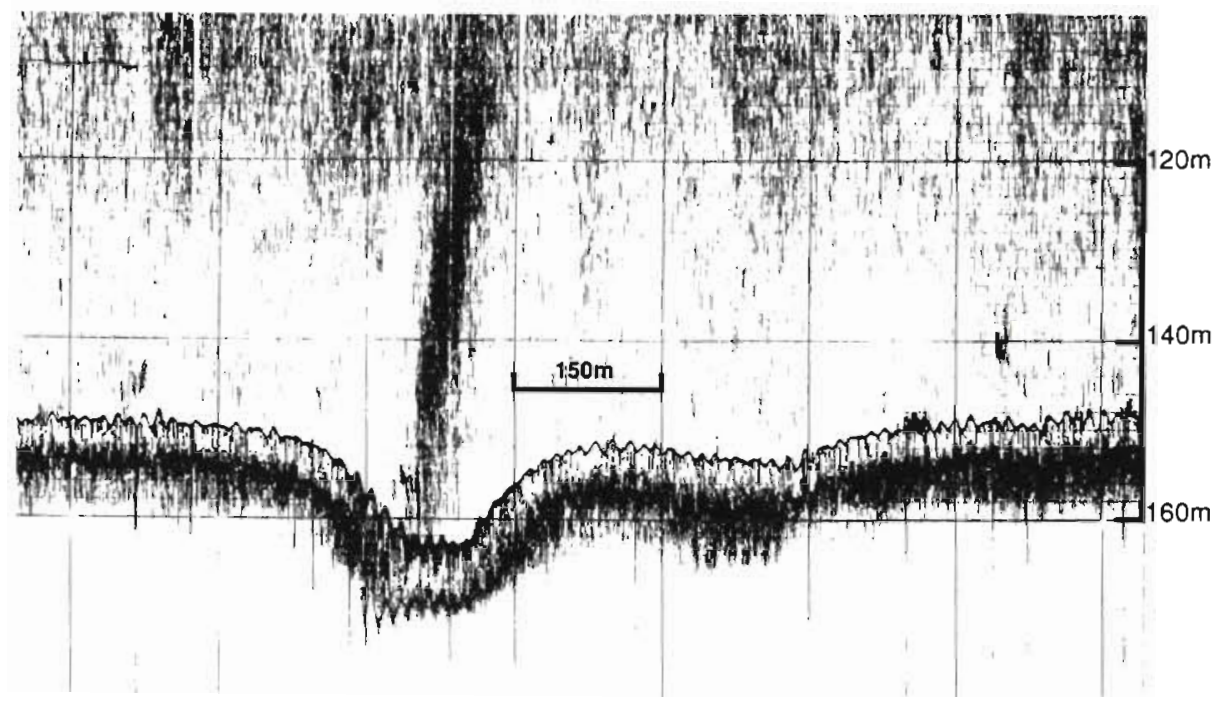

Fig. 3. Echo-sounding transect, at a frequency of $38 \mathrm{kHz}$, across the pockmark from SW to NE on 9 June 1989. A $60 \mathrm{~m}$ high plume of gas and/or sediment can be seen in the water column

isotope analysis of this cement gave a $\delta^{13} \mathrm{C}$ of $-36.1 \%$. $\mathrm{X}$-ray micro-analysis of typical sand grains (Fig. 4a) and dark mineral grains (Fig. 4c) in the rock showed that it contained potassium feldspar and pyrite particles: a sample of authentic pyrite is shown for compari-
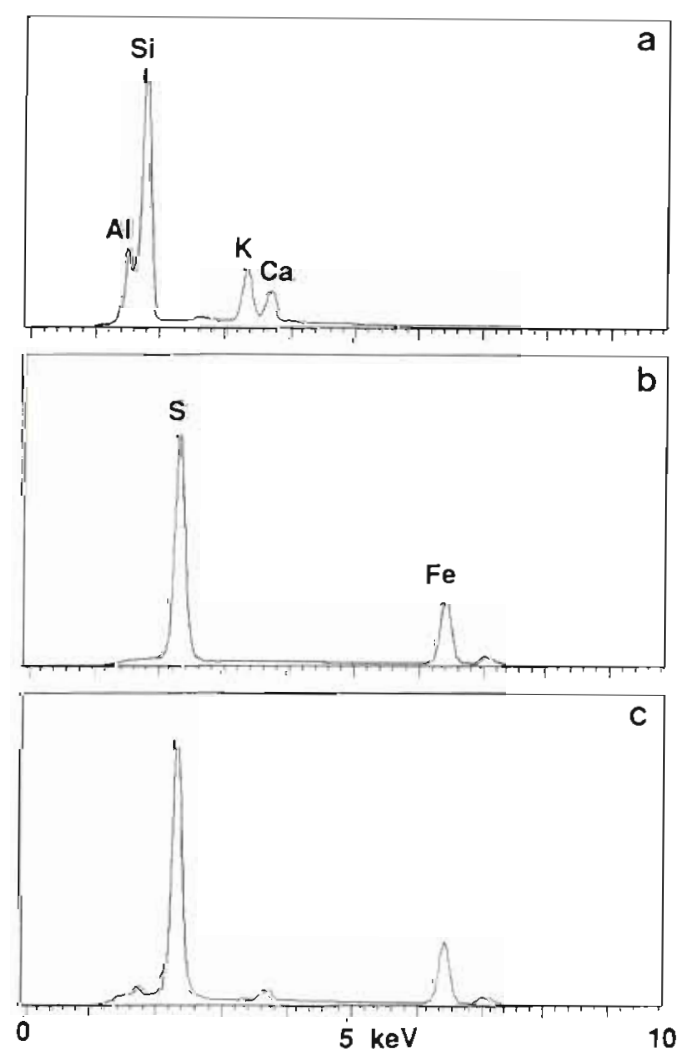

Fig. 4. X-ray elemental microanalysis of particles from the carbonate-cemented sand collected in the pockmark. (a) Typical sand grain; (b) authentic pyrite, $\mathrm{FeS}_{2 i}$ (c) dark mineral grain from cemented sand son in Fig. 4b. The calcium signal comes from the calcium carbonate cementing the particles together.

Sediment macrofauna species and their observed densities are listed in Table 1. Within the pockmark macro-infauna was most frequent where the underlying grey clay was covered by a poorly-consolidated brown silt. The firm clay in the bottom of the pockmark (R3, R6 and R7) contained few animals. Although the corer penetration was limited there, the greatly reduced number of individuals was most likely due to other factors. In samples from the sides of the pockmark at least $70 \%$ of the animals were present in the upper $10 \mathrm{~cm}$ section.

The macrofaunal community structure of the pockmark and its environs was examined using multidimensional scaling ordination (MDS). As only 5 individuals were taken in the 3 cores from the basal firm clay (R3, R6, and R7) these were excluded from the analysis. On the basis of the remaining samples there was no real difference in structure between the fauna on the sides of the pockmark (R1, R5, R8, S1 and S2) and that from the surrounding level bottom ( $\$ 4$, S5 and S6). Numerically, this assemblage was dominated by the polychaetes Paramphinome jeffreysi, Levinsenia gracilis, Heteromastus filiformis, Spiophanes kroyerii, the bivalve Thyasira equalis and juvenile echinoderms Echinocardium sp. These 6 species accounted for $65 \%$ of the total individuals. Although foraminifera were abundant they were not enumerated.

The total macrofauna abundance was heavily influenced by the numbers of juvenile Echinocardium $\mathrm{sp}$. These were abundant in the samples collected in June but had decreased substantially by July. The estimated dry weights of the macrofauna varied from 0.3 to $3.9 \mathrm{~g} \mathrm{~m}^{-2}$ (Table 1 ).

Sediment samples from the pockmark were distin- 
Table 1. Densities (no. $\mathrm{m}^{-2}$ ) for the macrofaunal species observed in box-core samples from the pockmark

\begin{tabular}{|c|c|c|c|c|c|c|c|c|c|c|c|}
\hline \multirow[t]{2}{*}{ Species } & \multicolumn{11}{|c|}{$\begin{array}{c}\text { Sample no. } \\
\text { (water depth, } \mathrm{m} \text { ) }\end{array}$} \\
\hline & $\begin{array}{c}\mathrm{S} 4 \\
(150)\end{array}$ & $\begin{array}{c}\text { S5 } \\
(150)\end{array}$ & $\begin{array}{c}S 6 \\
(150)\end{array}$ & $\begin{array}{l}\text { R5 } \\
\text { (153) }\end{array}$ & $\begin{array}{c}\text { R } 8 \\
(157)\end{array}$ & $\begin{array}{c}\mathrm{S} 1 \\
(157)\end{array}$ & $\begin{array}{l}\mathrm{R} 1 \\
(162)\end{array}$ & $\begin{array}{c}S 2 \\
(166)\end{array}$ & $\begin{array}{c}\mathrm{R} 3 \\
(167)\end{array}$ & $\begin{array}{l}\text { R6 } \\
(168)\end{array}$ & $\begin{array}{c}\mathrm{R} 7 \\
(168)\end{array}$ \\
\hline \multicolumn{12}{|l|}{ CNIDARIA } \\
\hline Pennatula phosphorea & 0 & 0 & 0 & 0 & 0 & 0 & 14 & 0 & 0 & 0 & 0 \\
\hline Virgularia mirabilis & 0 & 0 & 0 & 12 & 0 & 0 & 0 & 0 & 0 & 0 & 0 \\
\hline \multicolumn{12}{|l|}{ NEMERTEA } \\
\hline Nemertea sp. A & 50 & 0 & 40 & 12 & 12 & 20 & 54 & 0 & 0 & 0 & 0 \\
\hline Nemertea sp. B & 0 & 0 & 0 & 0 & 0 & 10 & 0 & 0 & 0 & 0 & 0 \\
\hline Nemertea sp. C & 30 & 0 & 0 & 0 & 0 & 0 & 0 & 10 & 0 & 0 & 0 \\
\hline Cerebratulus sp. & 10 & 0 & 0 & 0 & 0 & 0 & 0 & 0 & 0 & 0 & 0 \\
\hline \multicolumn{12}{|l|}{ ANNELIDA } \\
\hline \multicolumn{12}{|l|}{ Polychaeta } \\
\hline Polynoe scolopendrina & 0 & 0 & 0 & 0 & 0 & 0 & 0 & 0 & 0 & 0 & 12 \\
\hline Phyllodoce rosea & 0 & 10 & 0 & 0 & 0 & 0 & 0 & 0 & 0 & 0 & 0 \\
\hline Gyptis sp. & 0 & 50 & 0 & 0 & 0 & 0 & 0 & 0 & 0 & 0 & 0 \\
\hline Gattyana cirrosa & 0 & 0 & 0 & 12 & 0 & 10 & 0 & 0 & 0 & 0 & 0 \\
\hline Phloe inornata & 0 & 0 & 0 & 0 & 12 & 0 & 0 & 10 & 0 & 0 & 0 \\
\hline Glycera lapidum & 0 & 0 & 0 & 48 & 47 & 0 & 54 & 0 & 0 & 0 & 0 \\
\hline Glycera indet. & 20 & 10 & 0 & 0 & 0 & 0 & 0 & 30 & 0 & 0 & 0 \\
\hline Goniada norvegica & 0 & 0 & 0 & 0 & 0 & 20 & 0 & 0 & 0 & 0 & 0 \\
\hline Goniada maculata & 0 & 0 & 10 & 0 & 0 & 0 & 0 & 0 & 0 & 0 & 0 \\
\hline Exogone verugera & 0 & 0 & 0 & 0 & 12 & 0 & 0 & 0 & 0 & 0 & 0 \\
\hline Nephtys kirsivalensis & 50 & 0 & 20 & 36 & 47 & 0 & 41 & 0 & 0 & 0 & 0 \\
\hline Nephtys incisa & 0 & 0 & 0 & 12 & 0 & 0 & 0 & 0 & 0 & 0 & 0 \\
\hline Ceratocephale loveni & 10 & 0 & 0 & 0 & 0 & 0 & 0 & 20 & 0 & 0 & 0 \\
\hline Lumbrineris scopa & 0 & 20 & 0 & 24 & 35 & 10 & 27 & 0 & 0 & 0 & 0 \\
\hline Paronis fulgens & 0 & 0 & 0 & 0 & 70 & 0 & 0 & 0 & 0 & 0 & 0 \\
\hline Paramphinome jeffreysi & 130 & 0 & 50 & 24 & 94 & 310 & 14 & 10 & 0 & 0 & 0 \\
\hline Orbinia norvegica & 10 & 0 & 10 & 0 & 0 & 0 & 0 & 0 & 0 & 0 & 0 \\
\hline Levinsenia gracilis & 0 & 60 & 330 & 60 & 223 & 130 & 109 & 60 & 0 & 0 & 0 \\
\hline Prionospio malmgreni & 0 & 0 & 10 & 0 & 24 & 10 & 0 & 0 & 0 & 0 & 0 \\
\hline Prionospio cirrifera & 0 & 0 & 0 & 12 & 0 & 0 & 14 & 0 & 0 & 0 & 0 \\
\hline Laonice sarsi & 0 & 0 & 10 & 0 & 0 & 20 & 0 & 0 & 0 & 0 & 0 \\
\hline Spiophanes kroyeri & 0 & 360 & 150 & 108 & 94 & 130 & 68 & 50 & 0 & 0 & 0 \\
\hline Magelona alleni & 0 & 0 & 0 & 12 & 12 & 0 & 0 & 0 & 0 & 0 & 0 \\
\hline Brada villosa & 0 & 0 & 0 & 0 & 0 & 0 & 14 & 0 & 0 & 0 & 0 \\
\hline Notomastus latericus & 0 & 10 & 0 & 0 & 0 & 0 & 0 & 0 & 0 & 0 & 0 \\
\hline Heteromastus filiformis & 440 & 30 & 150 & 84 & 118 & 140 & 136 & 250 & 0 & 0 & 0 \\
\hline Maldanid sp. & 0 & 0 & 0 & 12 & 0 & 0 & 0 & 0 & 0 & 0 & 0 \\
\hline Myriochele oculata & 0 & 0 & 0 & 0 & 0 & 10 & 0 & 0 & 0 & 0 & 0 \\
\hline Ophelina limacina & 0 & 0 & 0 & 0 & 0 & 0 & 27 & 0 & 0 & 0 & 0 \\
\hline Ophelina norvegica & 0 & 20 & 20 & 0 & 0 & 10 & 0 & 0 & 0 & 0 & 0 \\
\hline Phylo norvegica & 0 & 30 & 0 & 0 & 0 & 0 & 0 & 0 & 0 & 0 & 0 \\
\hline Amphicteis gunneri & 0 & 0 & 10 & 0 & 0 & 0 & 0 & 0 & 0 & 0 & 0 \\
\hline Terebellides stroemi & 0 & 0 & 0 & 12 & 0 & 30 & 0 & 0 & 0 & 0 & 0 \\
\hline \multicolumn{12}{|l|}{ CRUSTACEA } \\
\hline \multicolumn{12}{|l|}{ Amphipoda } \\
\hline Ampelisca eschrichtii & 10 & 0 & 0 & 0 & 0 & 0 & 0 & 0 & 0 & 0 & 0 \\
\hline Byblis giamardi & 0 & 0 & 0 & 12 & 0 & 0 & 0 & 0 & 0 & 0 & 0 \\
\hline Eriopisa elongata & 0 & 90 & 20 & 0 & 0 & 0 & 0 & 0 & 0 & 0 & 0 \\
\hline Synchelidium maculatum & 0 & 0 & 10 & 0 & 0 & 0 & 0 & 0 & 0 & 0 & 0 \\
\hline Metopa alderi & 0 & 0 & 0 & 0 & 0 & 0 & 14 & 0 & 0 & 0 & 0 \\
\hline Harpinia antennaria & 60 & 20 & 40 & 36 & 24 & 0 & 41 & 10 & 0 & 0 & 0 \\
\hline Aoridae sp. & 0 & 0 & 0 & 0 & 0 & 0 & 28 & 0 & 0 & 0 & 0 \\
\hline \multicolumn{12}{|l|}{ Cumacea } \\
\hline Leucon nasica & 30 & 10 & 10 & 12 & 0 & 0 & 68 & 10 & 0 & 0 & 0 \\
\hline Eudorella truncatula & 0 & 0 & 0 & 12 & 0 & 0 & 0 & 0 & 0 & 0 & 0 \\
\hline \multicolumn{12}{|l|}{ Tanaidacea } \\
\hline Apseudes spinosus & 40 & 0 & 0 & 0 & 0 & 0 & 0 & 0 & 0 & 0 & 0 \\
\hline Araphura brevimana & 0 & 0 & 0 & 0 & 12 & 0 & 0 & 0 & 0 & 0 & 0 \\
\hline Typhlotanais aeqiremis & 0 & 0 & 40 & 0 & 0 & 0 & 0 & 0 & 0 & 0 & 0 \\
\hline
\end{tabular}


Table 1 (continued)

\begin{tabular}{|c|c|c|c|c|c|c|c|c|c|c|c|}
\hline \multirow[t]{2}{*}{ Species } & \multicolumn{11}{|c|}{$\begin{array}{c}\text { Sample no. } \\
\text { (water depth, m) }\end{array}$} \\
\hline & $\begin{array}{c}\mathrm{S} 4 \\
(150)\end{array}$ & $\begin{array}{c}\text { S5 } \\
(150)\end{array}$ & $\begin{array}{l}\text { S6 } \\
(150)\end{array}$ & $\begin{array}{l}\text { R } 5 \\
(153)\end{array}$ & $\begin{array}{l}\mathrm{R} 8 \\
(157)\end{array}$ & $\begin{array}{c}\text { S } 1 \\
(157)\end{array}$ & $\begin{array}{l}R_{1} \\
(162)\end{array}$ & $\begin{array}{l}52 \\
(166)\end{array}$ & $\begin{array}{l}\text { R3 } \\
(167)\end{array}$ & $\begin{array}{c}\mathrm{R} 6 \\
(168)\end{array}$ & $\begin{array}{c}\text { R7 } \\
(168)\end{array}$ \\
\hline \multicolumn{12}{|l|}{ Decapoda } \\
\hline Dichelopandalus bonnieri & 0 & 0 & 0 & 0 & 12 & 0 & 0 & 0 & 0 & 0 & 12 \\
\hline \multicolumn{12}{|l|}{$\begin{array}{l}\text { MOLLUSCA } \\
\text { Caudofoveata }\end{array}$} \\
\hline $\begin{array}{l}\text { Chaetoderma nitidulum } \\
\text { Gastropoda }\end{array}$ & 10 & 0 & 20 & 0 & 70 & 30 & 14 & 40 & 0 & 0 & 0 \\
\hline Natica alderi & 0 & 0 & 0 & 12 & 0 & 0 & 14 & 0 & 0 & 0 & 0 \\
\hline Pelecypoda & & & & & & & & & & & \\
\hline Nuculana minuta & 0 & 0 & 0 & 0 & 0 & 0 & 0 & 10 & 0 & 0 & 0 \\
\hline Parvicardium scabrum & 20 & 0 & 0 & 0 & 0 & 0 & 14 & 0 & 0 & 0 & 0 \\
\hline Abra nitida & 0 & 20 & 10 & 24 & 12 & 0 & 0 & 0 & 0 & 0 & 0 \\
\hline Thyasira croulinensis & 20 & 100 & 70 & 72 & 12 & 70 & 14 & 0 & 0 & 0 & 0 \\
\hline Thyasira equalis & 30 & 50 & 140 & 12 & 24 & 220 & 68 & 40 & 0 & 0 & 12 \\
\hline Thyasira ferruginea & 10 & 20 & 10 & 0 & 0 & 10 & 0 & 0 & 0 & 0 & 24 \\
\hline Thyasira sarsi & 0 & 0 & 0 & 0 & 24 & 70 & 0 & 0 & 0 & 0 & 0 \\
\hline Thyasira pygmaea & 10 & 0 & 0 & 0 & 0 & 10 & 0 & 0 & 0 & 0 & 0 \\
\hline Thyasira indet. & 0 & 20 & 0 & 12 & 24 & 0 & 27 & 10 & 0 & 0 & 0 \\
\hline PHORONIDA & & & & & & & & & & & \\
\hline Phoronis mulleri & 0 & 30 & 10 & 0 & 0 & 20 & 14 & 0 & 0 & 0 & 0 \\
\hline ECHINODERMATA & & & & & & & & & & & \\
\hline Amphiura sp. (juvenile) & 0 & 10 & 0 & 0 & 0 & 0 & 14 & 0 & 0 & 0 & 0 \\
\hline Echinocardium flavescens & 0 & 0 & 0 & 0 & 0 & 10 & 0 & 0 & 0 & 0 & 0 \\
\hline Echinocardium sp. (juv.) & 150 & 570 & 120 & 24 & 12 & 230 & 27 & 210 & 0 & 0 & 0 \\
\hline Total of species & 20 & 21 & 24 & 24 & 22 & 23 & 24 & 15 & 0 & 0 & 4 \\
\hline Total of individuals & 1140 & 1550 & 1310 & 708 & 1026 & 1530 & 929 & 770 & 0 & 0 & 60 \\
\hline Dry weight $\left(\mathrm{g} \mathrm{m}^{-2}\right)$ & 1.1 & 2.0 & 0.4 & 1.1 & 0.3 & 2.4 & 3.9 & 0.6 & 0 & 0 & nd \\
\hline
\end{tabular}

guished from those of the surrounding area because of the large number of fish otoliths present in the former. The density in 5 grab samples from the pockmark was $1550 \mathrm{~m}^{-2}$ (range 540 to $3690 \mathrm{~m}^{-2}$ ), compared to a single otolith from 5 grab samples from outside the pockmark, i.e. $2 \mathrm{~m}^{-2}$.

Animals collected in the Agassiz trawls included the pennatulacean Pennatula phosphorea, the molluscs Antalis entalis, Arctica islandica, Parvicardium scabrum, Abra nitida and Thyasira sarsi, the decapods Dichelopandalus bonnieri, Munida sp., Upogebia deltaura, and Macropipus holsatus, the echinoderm Echinocardium flavescens, and the fishes Myxine glutinosa, Rhinonema cimbrius, Melanogrammus aeglefinus, Sebastes viviparus and Hippoglossoides platessoides.

Meiofauna in the cores from both the bottom and sides of the pockmark was dominated by nematodes, and only this taxon was identified and enumerated. The species and densities for the nematodes in the 4 core samples examined are listed in Table 2. Both samples from the sides of the pockmark had more species, 69 for R5 and 75 for R1, than the samples from the base, 29 for R6 and 37 for R3. A mouthless and gutless nematode, Astomonema sp., was the dominant species in 3 of the 4 cores. It was particularly abundant in the 2 core samples, R1 and R5, from the side of the pockmark where it comprised $27 \%$ of the total nematodes. The distribution of this nematode with depth in the sediment of R1 is illustrated in Fig. 5a. A maximum in distribution at 5 to $8 \mathrm{~cm}$ depth coincides with a maximum in elemental sulphur content. $\mathrm{S}^{\circ}$ was the major form of reduced sulphur at this depth in the core. Sulphate reduction rates and total sulphide concentrations in the same core are shown in Fig. 5b

The locations of the sediment and water samples analyzed are shown in Fig. 1. There was no detectable hydrogen sulphide in any of the samples but high insoluble sulphide concentrations were present in many (Tables 3 and 4). Samples from the plateau, at a water depth of $150 \mathrm{~m}$, near the pockmark had low total reduced sulphur concentrations, 1 to $4 \mathrm{mg}$-at. $\mathrm{dm}^{-3}$ in 
Table 2. Densities (ind. $\mathrm{dm}^{-2}$ ) for the meiofaunal nematode species observed in sub-samples from box-core samples from the pockmark

\begin{tabular}{|c|c|c|c|c|}
\hline \multirow[t]{2}{*}{ Species } & \multicolumn{4}{|c|}{$\begin{array}{c}\text { Sample no. } \\
\text { (water depth, m) }\end{array}$} \\
\hline & $\begin{array}{c}\text { R5 } \\
(153)\end{array}$ & $\begin{array}{l}\text { R6 } \\
(157)\end{array}$ & $\begin{array}{c}\text { R 1 } \\
\text { (162) }\end{array}$ & $\begin{array}{c}\text { R3 } \\
(167)\end{array}$ \\
\hline \multicolumn{5}{|l|}{ Thoracostomopsidae } \\
\hline Saveljevia sp. & 0 & 0 & 14 & 0 \\
\hline Thoracostomopsis sp. & 9 & 0 & 0 & 0 \\
\hline Paramesacanthion hirsutum & 61 & 0 & 33 & 5 \\
\hline Trichenoplus sp. & 14 & 0 & 0 & 0 \\
\hline \multicolumn{5}{|l|}{ Phanodermatidae } \\
\hline Crenopharynx sp. & 5 & 0 & 19 & 0 \\
\hline \multicolumn{5}{|l|}{ Anticornidae } \\
\hline Cephalanticoma sp. & 0 & 0 & 5 & 0 \\
\hline \multicolumn{5}{|l|}{ Leptosomatidae } \\
\hline Cylicolaimus sp. & 14 & 0 & 0 & 0 \\
\hline cf. Platycoma sp. & 5 & 0 & 0 & 0 \\
\hline \multicolumn{5}{|l|}{ Oxystominidae } \\
\hline Halalaimus isaitshikovi & 0 & 0 & 9 & 0 \\
\hline Halalaimus longicaudatus & 122 & 5 & 19 & 0 \\
\hline Halalaimus sp. 1 & 146 & 14 & 113 & 0 \\
\hline Halalaimus sp. 2 & 14 & 0 & 19 & 0 \\
\hline Halalaimus sp. 3 & 28 & 0 & 42 & 0 \\
\hline Litinium sp. & 9 & 0 & 0 & 0 \\
\hline Oxystomina sp. & 14 & 0 & 14 & 0 \\
\hline Wieseria sp. & 14 & 0 & 5 & 0 \\
\hline \multicolumn{5}{|l|}{ Oncholaimidae } \\
\hline Oncholaimid cf. Pontema sp. & 5 & 5 & 5 & 108 \\
\hline Oncholaimid sp. A & 0 & 0 & 9 & 5 \\
\hline Viscosia abyssorum & 14 & 0 & 9 & 0 \\
\hline Viscosia sp. 2 & 47 & 0 & 89 & 9 \\
\hline \multicolumn{5}{|l|}{ Enchelidiidae } \\
\hline Calyptronema sp. & 0 & 0 & 5 & 0 \\
\hline Ditlevsenella sp. & 0 & 0 & 0 & 9 \\
\hline Symplocostoma sp. 1 & 9 & 0 & 0 & 0 \\
\hline Symplocostoma sp. 2 & 9 & 0 & 0 & 0 \\
\hline \multicolumn{5}{|l|}{ Rhabdodemaniidae } \\
\hline Rhabdodemania Inajor & 61 & 14 & 141 & 28 \\
\hline \multicolumn{5}{|l|}{ Trefusiidae } \\
\hline Rhabdocoma americana & 132 & 5 & 122 & 9 \\
\hline \multicolumn{5}{|l|}{ Chromadoridae } \\
\hline Acantholaimus sp. & 0 & 0 & 14 & 0 \\
\hline Actinonema pachydermatum & 24 & 9 & 47 & 5 \\
\hline Chromadorita sp. & 254 & 5 & 113 & 24 \\
\hline Spilophorella sp. & 165 & 0 & 33 & 0 \\
\hline \multicolumn{5}{|l|}{ Comesomatidae } \\
\hline Cervonema sp. & 184 & 0 & 9 & 0 \\
\hline Dorylaimopsis punctata & 24 & 14 & 471 & 85 \\
\hline cf. Hopperia sp. & 24 & 0 & 0 & 0 \\
\hline Laimella sp. & 14 & 0 & 0 & 0 \\
\hline Pierrickia sp. & 0 & 0 & 5 & 0 \\
\hline Sabatieria punctata & 231 & 9 & 184 & 9 \\
\hline Sabatieria sp. 1 & 235 & 24 & 264 & 19 \\
\hline Sabatieria sp. 2 & 80 & 0 & 0 & 5 \\
\hline Setosabatieria sp. & 14 & 0 & 0 & 14 \\
\hline \multicolumn{5}{|l|}{ Ethmolaimidae } \\
\hline Comesa/Neotonchus sp. & 71 & 0 & 52 & 0 \\
\hline
\end{tabular}

Table 2 (continued)

\begin{tabular}{|c|c|c|c|c|}
\hline \multirow[t]{2}{*}{ Species } & \multicolumn{4}{|c|}{$\begin{array}{c}\text { Sample no. } \\
\text { (water depth, m) }\end{array}$} \\
\hline & $\begin{array}{c}\text { R5 } \\
(153)\end{array}$ & $\begin{array}{c}\text { R6 } \\
(157)\end{array}$ & $\begin{array}{c}\text { R 1 } \\
(162)\end{array}$ & $\begin{array}{c}\text { R3 } \\
\text { (167) }\end{array}$ \\
\hline \multicolumn{5}{|l|}{ Cyatholaimidae } \\
\hline Marylinnia sp. & 0 & 0 & 9 & 9 \\
\hline Minolaimus sp. & 0 & 5 & 14 & 0 \\
\hline Longicyatholaimus sp. & 14 & 0 & 0 & 0 \\
\hline Paralongicyatholaimus sp. & 0 & 0 & 0 & 5 \\
\hline Pomponema multipapillatum & 33 & 9 & 33 & 9 \\
\hline \multicolumn{5}{|l|}{ Salachinematidae } \\
\hline Halichoanalaimus sp. & 19 & 5 & 0 & 0 \\
\hline Synonchiella riemani & 0 & 0 & 5 & 0 \\
\hline \multicolumn{5}{|l|}{ Desmodoridae } \\
\hline Desmodora sp. & 0 & 0 & 5 & 5 \\
\hline Desmodora tenuispiculum & 0 & 5 & 0 & 0 \\
\hline \multicolumn{5}{|l|}{ Microlaimidae } \\
\hline cf. Aponema sp. & 9 & 0 & 0 & 0 \\
\hline Calamicrolaimes honestus & 0 & 0 & 0 & 5 \\
\hline Microlaimus sp. & 0 & 0 & 5 & 0 \\
\hline \multicolumn{5}{|l|}{ Leptolaimidae } \\
\hline Antomicron sp. & 9 & 5 & 14 & 0 \\
\hline Camacolaimus sp. & 38 & 5 & 5 & 0 \\
\hline Leptolaimus cf. elegans & 141 & 9 & 325 & 24 \\
\hline Leptolaimus sp. & 636 & 24 & 184 & 9 \\
\hline Onchium sp. & 0 & 0 & 14 & 9 \\
\hline \multicolumn{5}{|l|}{ Aegialoalaimidae } \\
\hline $\begin{array}{l}\text { Aegialoalaimus/ } \\
\text { Cyartonema sp. }\end{array}$ & 33 & 0 & 57 & 5 \\
\hline Diplopeltoides sp. & 9 & 0 & 38 & 5 \\
\hline \multicolumn{5}{|l|}{ Ceramonematidae } \\
\hline Pselionema sp. & 19 & 0 & 24 & 0 \\
\hline \multicolumn{5}{|l|}{ Desmoscolecidae } \\
\hline Desmoscolex sp. & 14 & 0 & 5 & 0 \\
\hline Quadricoma sp. & 19 & 0 & 71 & 0 \\
\hline Tricoma sp. & 14 & 0 & 38 & 0 \\
\hline \multicolumn{5}{|l|}{ Monohysteridae } \\
\hline Monhystera refringens & 0 & 0 & 5 & 0 \\
\hline Monhysterid sp. 1 & 71 & 5 & 38 & 9 \\
\hline Monhysterid sp. 2 & 0 & 0 & 33 & 0 \\
\hline \multicolumn{5}{|l|}{ Xyalidae } \\
\hline Ammotheristus sp. & 9 & 0 & 0 & 0 \\
\hline Amphimonhystrella sp. & 14 & 5 & 24 & 0 \\
\hline Daptonema setosa & 0 & 0 & 14 & 0 \\
\hline Daptonema sp. A & 71 & 5 & 80 & 5 \\
\hline Daptonema sp. B & 14 & 0 & 42 & 0 \\
\hline Daptonema sp. C & 14 & 0 & 0 & 0 \\
\hline Gnomoxyala sp. & 5 & 0 & 24 & 0 \\
\hline Theristus sp. & 0 & 0 & 0 & 5 \\
\hline \multicolumn{5}{|l|}{ Sphaerolaimidae } \\
\hline Parasphaerolaimus sp. & 14 & 0 & 71 & 0 \\
\hline Spaerolaimus islandicus & 14 & 5 & 38 & 5 \\
\hline Sphaerolaimus macrocirculus & 33 & 5 & 89 & 0 \\
\hline Sphaerolaimus sp. (juvenile) & 155 & 0 & 0 & 9 \\
\hline Sphaerolaimus sp. & 42 & 0 & 19 & 0 \\
\hline Subsphaerolaimus sp. & 0 & 0 & 5 & 0 \\
\hline \multicolumn{5}{|l|}{ Siphanolaimidae } \\
\hline Astomonema sp. & 2251 & 33 & 1168 & 5 \\
\hline Siphonolaimus sp. & 9 & 0 & 0 & 0 \\
\hline
\end{tabular}


Table 2 (continued)

\begin{tabular}{|c|c|c|c|c|}
\hline \multirow[t]{2}{*}{ Species } & \multicolumn{4}{|c|}{$\begin{array}{c}\text { Sample no. } \\
\text { (water depth, m) }\end{array}$} \\
\hline & $\begin{array}{l}\text { R5 } \\
\text { (153) }\end{array}$ & $\begin{array}{l}\mathrm{R} 6 \\
(157)\end{array}$ & $\begin{array}{c}\text { R 1 } \\
(162)\end{array}$ & $\begin{array}{c}\text { R3 } \\
\text { (167) }\end{array}$ \\
\hline \multicolumn{5}{|l|}{ Linhomoedidae } \\
\hline Eleutherolaimus sp. & 14 & 0 & 0 & 0 \\
\hline Eumorpholaimus sp. & 14 & 0 & 0 & 0 \\
\hline Linhomoeus sp. & 0 & 0 & 0 & 5 \\
\hline Metalinhomoeus sp. & 28 & 5 & 0 & 5 \\
\hline $\begin{array}{l}\text { Paralinhomoeus cf. } \\
\text { tenuicaudatus }\end{array}$ & 0 & 0 & 9 & 0 \\
\hline Paralinhomoeus sp. & 306 & 0 & 245 & 9 \\
\hline Terschellingia longicaudata & 0 & 5 & 42 & 0 \\
\hline Terschellingia sp. & 212 & 5 & 52 & 5 \\
\hline \multicolumn{5}{|l|}{ Axonolaimidae } \\
\hline Axonolaimus sp. & 33 & 9 & 75 & 5 \\
\hline Odontophora sp. & 0 & 9 & 0 & 0 \\
\hline \multicolumn{5}{|l|}{ Diplopeltidae } \\
\hline Campylaimus sp. & 9 & 0 & 24 & 0 \\
\hline Diplopeltula sp. & 0 & 0 & 5 & 5 \\
\hline Southerniella sp. & 0 & 0 & 14 & 0 \\
\hline \multicolumn{5}{|l|}{ Miscellaneous } \\
\hline $\mathrm{sp} . \mathrm{B}$ & 0 & 0 & 0 & 5 \\
\hline sp. D & 0 & 0 & 5 & 0 \\
\hline sp. E & 28 & 0 & 0 & 0 \\
\hline sp. F & 0 & 0 & 5 & 0 \\
\hline sp. H & 0 & 0 & 5 & 0 \\
\hline sp. J & 28 & 0 & 24 & 0 \\
\hline sp. K & 0 & 0 & 9 & 0 \\
\hline sp. M & 0 & 0 & 5 & 0 \\
\hline sp. P & 0 & 0 & 9 & 0 \\
\hline$s p \cdot Q$ & 0 & 0 & 5 & 0 \\
\hline Unidentified & 768 & 14 & 490 & 57 \\
\hline Total taxa & 69 & 29 & 75 & 37 \\
\hline Total individuals & 7191 & 323 & 5336 & 548 \\
\hline
\end{tabular}

the upper $10 \mathrm{~cm}$ of the sediment (Table 4); the one exception being S9. S9 was taken close to an active methane seep, in a small pockmark $1 \mathrm{~km}$ north of the main site investigated, and had a sulphide concentration of $33 \mathrm{mg}$-at. $\mathrm{S} \mathrm{dm}{ }^{-3}$ at $10 \mathrm{~cm}$ sediment depth. Changes in the reduced sulphur concentration with depth were noticeably erratic in cores from the side of the pockmark, R1, R5 and R8, when compared with cores from the bottom of the pockmark or the surrounding plateau.

Methane concentrations were low in R1 from the side of the pockmark (Fig. 5c). The concentrations varied from $<5 \mathrm{nmol} \mathrm{dm}{ }^{-3}$ in the upper $10 \mathrm{~cm}$ of sediment to

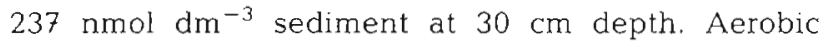
methane oxidation was $0.42 \pm 0.19 \mu \mathrm{mol} \mathrm{dm}^{-3}$ sediment $\mathrm{h}^{-1}(\mathrm{n}=5)$ in the upper $6 \mathrm{~cm}$ of sediment in samples from R1 No oxidation was detected below this depth in the core. Neither methane nor aerobic methane oxidation could be detected in the upper $10 \mathrm{~cm}$ of sediment from $\mathrm{R} 6$ from the pockmark base.
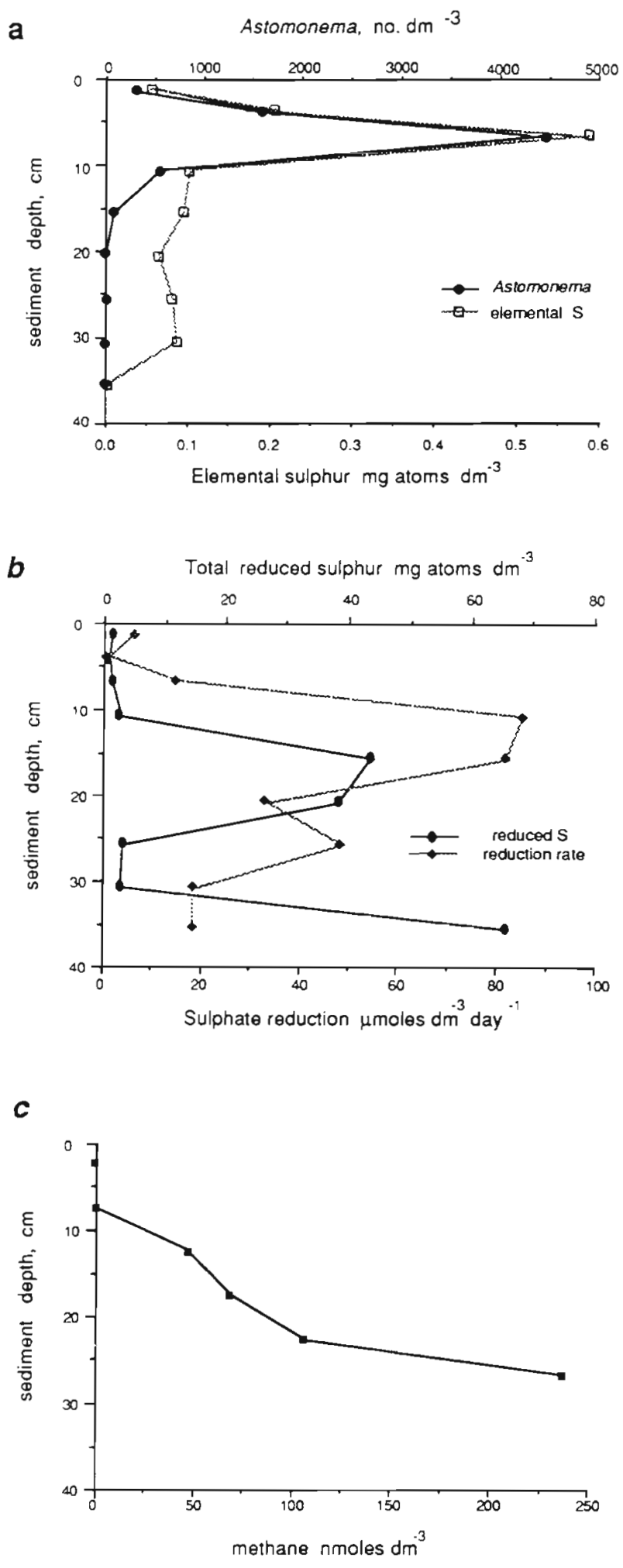

Fig. 5. Distribution of Astomonema sp., elemental sulphur, total sulphide, sulphate reduction rate and methane in core sample R1 from the side of the pockmark. (a) Depth distribution of Astomonema and elemental sulphur, (b) depth distribution of total reduced sulphur and sulphate reduction rate, (c) depth distribution of methane 
Table 3. Reduced sulphur compounds in sediment samples from the MV 'Resolution' cruise (11 July 1989)

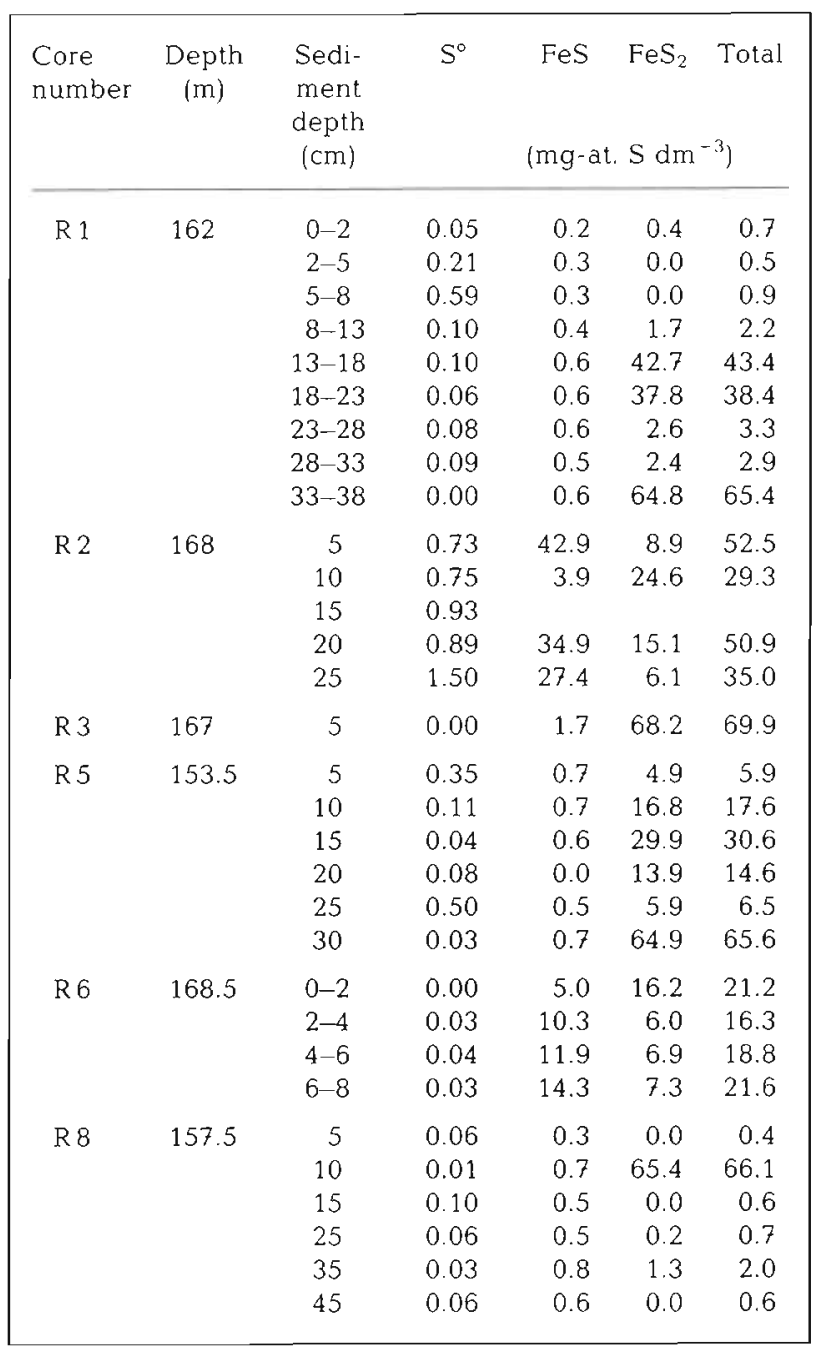

Methane concentrations observed in the water column are plotted against water depth in Fig. 6. The concentrations were in the range $<0.5$ to $60 \mathrm{nM}$. The highest concentrations were found in the samples taken close to the pockmark areas where the echo sounder suggested that gas bubbles were present in the water column (Fig. 3). The carbon isotope compositions of the fauna in and around the pockmark and the composition of the organic carbon and carbonate in the sediment from R1 and R5 are given in Tables $5 \& 6$ respectively.

\section{DISCUSSION}

Sediments from the large pockmark are characterized by the presence of high total sulphide concentrations in the surface layers, as compared to surrounding areas. No hydrogen sulphide odour was detected in
Table 4. Total reduced sulphur in sediment samples from FRV 'Scotia' (9 June 1989)

\begin{tabular}{|c|c|c|c|}
\hline $\begin{array}{l}\text { Sample } \\
\text { number }\end{array}$ & $\begin{array}{l}\text { Depth } \\
(\mathrm{m})\end{array}$ & $\begin{array}{l}\text { Sediment } \\
\text { depth } \\
\text { (cm) }\end{array}$ & $\begin{array}{c}\text { Total } \mathrm{S}^{2-} \\
\left(\mathrm{mg}-\mathrm{at} . \mathrm{dm}^{-3}\right)\end{array}$ \\
\hline S 1 & 157 & 5 & 18.8 \\
\hline S 1 & 157 & 10 & 37.9 \\
\hline S 2 & 166 & 5 & 0.7 \\
\hline S 2 & 166 & 10 & 25.3 \\
\hline S3 & 166 & 5 & 1.7 \\
\hline S 3 & 166 & 10 & 38.7 \\
\hline $\mathrm{S} 4$ & 150 & 5 & 1.5 \\
\hline $\mathrm{S} 4$ & 150 & 10 & 4.0 \\
\hline S5 & 150 & 5 & 1.1 \\
\hline S 5 & 150 & 10 & 3.1 \\
\hline S6 & 150 & 5 & 2.7 \\
\hline S 6 & 150 & 10 & 5.0 \\
\hline S7 & 150 & 5 & 2.5 \\
\hline 57 & 150 & 10 & 3.8 \\
\hline S8 & 150 & 5 & 1.7 \\
\hline S 8 & 150 & 10 & 1.8 \\
\hline S 9 & 150 & 5 & 1.8 \\
\hline S9 & 150 & 10 & 32.8 \\
\hline S 10 & 150 & 5 & 2.8 \\
\hline $\mathrm{S} 10$ & 150 & 10 & 1.8 \\
\hline S 10 & 150 & 15 & 4.0 \\
\hline S 10 & 150 & 20 & 1.8 \\
\hline $\mathrm{S} 10$ & 150 & 5 & 2.6 \\
\hline S 10 & 150 & 10 & 1.6 \\
\hline $\mathrm{S} 10$ & 150 & 15 & 4.5 \\
\hline $\mathrm{S} 10$ & 150 & 20 & 16.6 \\
\hline S 10 & 150 & 25 & 22.6 \\
\hline S 10 & 150 & 5 & 4.1 \\
\hline S 10 & 150 & 10 & 5.5 \\
\hline S 10 & 150 & 20 & 6.4 \\
\hline S 10 & 150 & 25 & 26.8 \\
\hline$S 10$ & 150 & 5 & 3.5 \\
\hline S 10 & 150 & 10 & 2.9 \\
\hline $\mathrm{S} 10$ & 150 & 20 & 0.3 \\
\hline S 11 & 150 & 10 & 2.9 \\
\hline S 11 & 150 & 15 & 10.5 \\
\hline $\mathrm{S} 11$ & 150 & 20 & 30.5 \\
\hline S 11 & 150 & 25 & 20.5 \\
\hline $\mathrm{S} 11$ & 150 & 30 & 30.5 \\
\hline $\mathrm{S} 11$ & 150 & 34 & 32.5 \\
\hline
\end{tabular}

any of the sediment samples, implying that the concentration of free sulphide was less than $0.1 \mu \mathrm{M}$ (Dando et al. 1985). The higher sulphide levels may be due to an increased sulphate reduction rate, commonly found in hydrocarbon-rich sediments (Ivanov et al. 1989), or to the removal of the surface sediments and exposure of older sediments rich in sulphide. The sulphate reduction rate was measured in only one core, $\mathrm{R} 1$. This rate was $6.8 \mathrm{mmol} \mathrm{m}^{-2} \mathrm{~d}^{-1}$, when integrated over the upper $15 \mathrm{~cm}$ of sediment for comparison with the values 

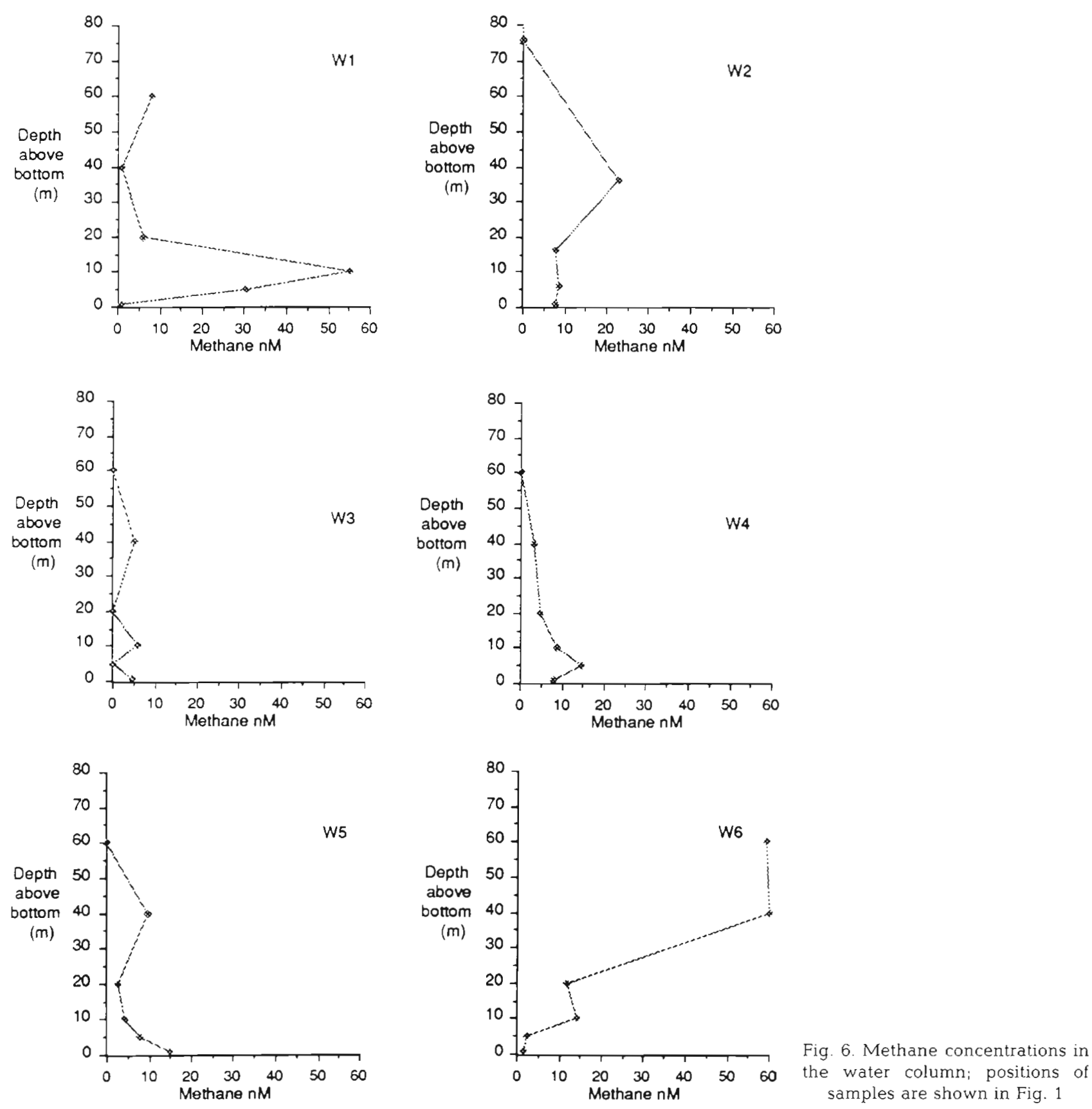

reported by Jørgensen (1989) for the North Sea off the Danish and German coasts. The highest rate reported by Jørgensen was $30 \mathrm{mmol} \mathrm{m} \mathrm{m}^{-2} \mathrm{~d}^{-1}$ from sediment off the mouth of the river Elbe. The other values reported for a variety of sediments from the North Sea and Skagerrak were in the range 0.02 to $17.4 \mathrm{~m}^{-2} \mathrm{~d}^{-1}$. It should be noted that the rates calculated by Jørgensen are low because radiolabelled $\mathrm{FeS}_{2}$ and $\mathrm{S}^{\circ}$ were not determined. The underestimation could be as high as $68 \%$ in samples from deeper water (Sørensen \& Jørgensen 1987).
The sulphate reduction rate in the core peaked at ca $10 \mathrm{~cm}$ sediment depth (Fig. 5b), coinciding with the disappearance of upward-diffusing methane (Fig. 5c). Anaerobic methane oxidation rates have been shown to reach a maximum at depths coinciding with a peak in sulphate reduction activity in sediments from the Skagerrak (Iversen \& Jorgensen 1985). These anaerobic methane oxidation rates of 0.8 to $1.1 \mathrm{mmol}$ methane $\mathrm{m}^{-2} \mathrm{~d}^{-1}$ were of the same order as the aerobic methane oxidation rate found for the surface sediments in $R 1,0.6$ mmol methane $\mathrm{m}^{-2} \mathrm{~d}^{-1}$. The presence of aerobic 
Table 5. Carbon isotope ratios for the macrofaunal species

\begin{tabular}{|c|c|c|c|}
\hline Species & Gear & Tissues & $\delta^{13} \mathrm{C}$ \\
\hline \multicolumn{4}{|l|}{ CNIDARIA } \\
\hline Pennatula phosphorea 1 & Trawl & All $^{a}$ & -22.8 \\
\hline Pennatula phosphorea 2 & Trawl & All & -21.0 \\
\hline \multicolumn{4}{|l|}{ NEMERTEA } \\
\hline Nemertean sp. & Trawl & All & -17.3 \\
\hline \multicolumn{4}{|l|}{ ANNELIDA } \\
\hline \multicolumn{4}{|l|}{ Polychaeta } \\
\hline Nephtys sp. 1 & Box core & All & -17.0 \\
\hline Nephtys sp. 2 & Trawl & All & -17.0 \\
\hline Goniada norvegica & Trawl & All & -15.9 \\
\hline Spiochaetopterus sp. & Trawl & Tube & -18.1 \\
\hline Unidentified polychaete 1 & Box core & All & -19.1 \\
\hline Unidentified polychaete 2 & Trawl & All & -19.7 \\
\hline Unidentified polychaete 3 & Trawl & All & -19.5 \\
\hline \multicolumn{4}{|l|}{ CRUSTACEA } \\
\hline \multicolumn{4}{|l|}{ Decapoda } \\
\hline Dichelopandalus bonnieri 1 & Trawl & Muscle & -17.0 \\
\hline Dichelopandalus bonnieri 2 & Trawl & Muscle & -17.0 \\
\hline Munida sp. & Box core & All & -20.4 \\
\hline Upogebia deltaura & Trawl & Muscle & -19.0 \\
\hline Macropipus holsatus 1 & Traw! & Muscle & -18.0 \\
\hline Macropipus holsatus 2 & Trawl & Muscle & -17.7 \\
\hline \multicolumn{4}{|l|}{ MOLLUSCA } \\
\hline \multicolumn{4}{|l|}{ Gastropoda } \\
\hline Fusus islandicus & Trawl & All & -17.5 \\
\hline \multicolumn{4}{|l|}{ Scaphopoda } \\
\hline Antalis entalis & Trawl & All & -19.2 \\
\hline Antalis entalis & Trawl & Shell & +0.2 \\
\hline \multicolumn{4}{|l|}{ Pelecypoda } \\
\hline Arctica islandica & Trawl & All & -19.0 \\
\hline Arctica islandica & Trawl & Shell & +0.6 \\
\hline Parvicardium scabrum 1 & Box core & All & -20.1 \\
\hline Parvicardium scabrum 1 & Box core & Shell & -1.0 \\
\hline Parvicardium scabrum 2 & Trawl & All & -19.2 \\
\hline Parvicardium scabrum 2 & Trawl & Shell & -1.4 \\
\hline Abra nitida 1 & Trawl & All & -18.4 \\
\hline Abra nitida 1 & Trawl & Shell & -1.0 \\
\hline Abra nitida 2 & Trawl & All & -18.4 \\
\hline Abra nitida 2 & Trawl & Shell & -0.6 \\
\hline Thyasira sarsi 1 & Box core & Gill & -34.3 \\
\hline Thyasira sarsi 1 & Box core & Adductor muscle & -35.1 \\
\hline Thyasira sarsi 1 & Box core & Digestive diverticula & -34.7 \\
\hline Thyasira sarsi 1 & Box core & Shell & -5.0 \\
\hline Thyasira sarsi 2 & Trawl & All & -31.4 \\
\hline Thyasira sarsi 2 & Trawl & Shell & -4.8 \\
\hline Thyasira sarsi 3 & Trawl & All & -33.8 \\
\hline \multicolumn{4}{|l|}{ ECHINODERMATA } \\
\hline Echinocardium flavescens & Trawl & All & -22.9 \\
\hline \multicolumn{4}{|l|}{ HEMICHORDATA } \\
\hline Enteropneust 1 & Trawl & Trunk & -17.6 \\
\hline Enteropneust 2 & Trawl & Head & -16.5 \\
\hline \multicolumn{4}{|l|}{ PISCES } \\
\hline Myxine glutinosa & Trawl & Muscle & -17.9 \\
\hline Myxine glutinosa & Trawl & Ovary & -20.4 \\
\hline Rhinonemus cimbrius & Trawl & Muscle & -16.9 \\
\hline Melanogrammus aeglefinus & Trawl & Muscle & $-17.2,-17.4$ \\
\hline Sebastes viviparus & Trawl & Muscle & -19.4 \\
\hline Hippoglossoides platessoides & Trawl & Muscle & -18.1 \\
\hline All = all decalcified soft tissues & & & \\
\hline
\end{tabular}


Table 6 . Sediment carbon content and $\delta^{13} \mathrm{C}$ ratios of organic and inorganic carbon

\begin{tabular}{|c|c|c|c|c|c|}
\hline Core number & $\begin{array}{l}\text { Sediment depth } \\
(\mathrm{cm})\end{array}$ & \multicolumn{2}{|c|}{ Organic $\underset{\text { (weight } \% \text { ) }}{\mathrm{C}} \mathrm{CaCO}_{3}$} & \multicolumn{2}{|c|}{$\delta^{13} \mathrm{C} \%$} \\
\hline$R 1$ & $0-2$ & 1.5 & 22.0 & -21.3 & -0.4 \\
\hline R 1 & $2-4$ & 1.4 & 20.8 & -21.0 & 0.3 \\
\hline R 1 & $5-7$ & 1.4 & 19.7 & -21.0 & 0.4 \\
\hline R 1 & $10-12$ & 1.4 & 19.4 & -21.9 & 0.1 \\
\hline R 1 & $13-15$ & 1.2 & 21.7 & -20.7 & 0.3 \\
\hline R 1 & $18-20$ & 1.4 & 21.5 & -19.7 & 0.3 \\
\hline R 1 & $23-28$ & 1.4 & 20.9 & -20.7 & 0.3 \\
\hline $\mathrm{R} 1$ & $28-30$ & 1.6 & 17.1 & -20.3 & -0.2 \\
\hline R 1 & $33-35$ & 1.5 & 20.8 & -20.8 & -0.2 \\
\hline R 5 & $4-6$ & 1.6 & 19.7 & -21.5 & 0.3 \\
\hline R 5 & $9-11$ & 1.4 & 18.8 & -21.3 & 0.4 \\
\hline R 5 & $14-16$ & 1.3 & 19.0 & -20.8 & 0.3 \\
\hline R 5 & $19-21$ & 1.3 & 23.3 & -21.7 & 0.2 \\
\hline R 5 & $24-26$ & 1.5 & 18.6 & -20.0 & 0.4 \\
\hline R 5 & $29-31$ & 1.5 & 17.8 & -20.7 & 0.4 \\
\hline R 5 & $34-36$ & 1.3 & 19.2 & -20.8 & 0.3 \\
\hline
\end{tabular}

methane oxidation in the surface layers suggests that some methane must be reaching the surface.

The high ratio of acid-labile sulphide to chromous reducible sulphide in several of the samples from the bottom of the pockmark supports the sulphate reduction studies and indicates that much of the reduced sulphur is of recent origin. Sulphide in deeper sediments would be expected to be present mainly as chromous reducible sulphide. However, sediment from the side of the pockmark showed great patchiness in the concentration of insoluble sulphides - as much as 2 orders of magnitude difference between sequential samples from a sub-core (Table 3 ). This may be due to physical displacement of sediment from elsewhere in the pockmark by gas or liquid expulsion or to lateral seepage of hydrocarbons. These extreme variations in sulphide concentrations are generally associated with sporadic distribution of organic matter in the sediment. The large number of fish otoliths in the pockmark suggests that there have been several massive displacements of sediment followed by winnowing of the lighter fractions. It is therefore probable that the high sulphide concentrations are due to a combination of enhanced reduction rate and to the removal of the surface, more aerobic, clays.

Sulphide-rich sediments enable thyasirid bivalves with chemoautotrophic sulphur-oxidising bacteria (Dando \& Southward 1986), Thyasira sarsi and $T$. equalis, to thrive in the pockmark sediments. T. sarsi has also been found at methane seeps in the Skagerrak at $300 \mathrm{~m}$ depth, where it is associated with the pogonophore Siboglinum poseidoni, an animal obtaining nutrition from endosymbiotic methane-oxidising bacteria (Schmaljohann et al. 1990). T. sarsi is generally found in association with organic-rich sediments with high total sulphide concentrations. It is common in several fjords along the Norwegian coast (Dando \& Southward 1986). This species has not previously been described from the Fladen Ground. Neither has it been recorded from other non-hydrocarbon-enriched muddy sediments in the Skagerrak or North Sea (McIntyre 1961, Petersen 1977, Josefson 1985). An exception is a single specimen found by Petersen in a sample from $165 \mathrm{~m}$ in the region of the Skaggerak known to have methane seeps. Shell lengths of up to $20 \mathrm{~mm}$, the maximum size of the species in Europe (Jensen \& Spärck 1934), were collected, suggesting the pockmark provides a good habitat for this thyasirid. T. equalis is also abundant elsewhere on the Fladen Ground (McIntyre 1961). The latter species appears to have less dependence than $T$. sarsi on sulphur-oxidising symbiotic bacteria, based on the activity of ribulosebisphosphate carboxylase and the number of bacteria in the gills (Dando \& Southward 1986, Southward 1986).

Carbonate-cemented sediment slabs from the base of this pockmark were described by Hovland \& Irwin (1989). A retrieved portion contained small compartments enclosing pyrite framboids. The carbonate had a $\delta^{13} \mathrm{C}$ value of $-51.5 \%$ compared with $-71 \%$ for the escaping methane gas. The sample retrieved on the 'Resolution' cruise was heavier, $-36.1 \%$, indicating smaller input from authigenic carbonate. Gas plumes were observed on acoustic records when the pockmark was first surveyed in 1983 (Hovland \& Sommerville 1985) and have been seen in subsequent surveys in 1985 (Hovland \& Judd 1988), as well as during this study. The gas efflux is probably responsible for preventing accumulation of fine sediment in the bottom of the pockmark.

The macrofauna samples (Table 1) show that there is 
a rapid transition from a very scarce fauna in the stiff clay at the base of the pockmark to the normal fauna of the Fladen Ground. This is illustrated by comparing R3, R6 and R7, at 167 to $168 \mathrm{~m}$ water depth, with R1 and S2, at 162 to $166 \mathrm{~m}$. The rapid change presumably relates to the presence or absence of consolidated clay in the surface layers. Even in the softer sediments there was no evidence of deep burrow systems in the box core samples, indicating that an extensive deep-burrowing fauna was not present. Adult bivalves and brittle stars were noticeable by their absence and only a few specimens were collected in the Agassiz trawls.

There are 2 comprehensive studies of the benthic macrofauna in this sector of the North Sea (Hartley 1984, Eleftheriou \& Basford 1989) and a study of the benthic fauna of the Fladen Ground by McIntyre (1961). The survey by Eleftheriou \& Basford can be used for comparison since it is based on single $0.1 \mathrm{~m}^{2}$ grab samples sieved through a $0.5 \mathrm{~mm}$ mesh. Of 76 stations sampled in the survey only 4 had less than 30 species, with the lowest number being 25 . This compares with 15 to 24 species (for comparative purposes all the thyasirids in our samples were counted as a single species) in the 8 samples from the softer sediments in the region of the pockmark, and 0 to 4 species from the 3 samples taken from the base. The 8 samples from the soft mud contained 708 to 1550 ind. $\mathrm{m}^{-2}$; the pockmark sample with the greatest density of individuals (S1) came from the edge of the pockmark. Only 3 of Eleftheriou \& Basford's 76 samples contained lower numbers of individuals. A better comparison with the latter study is to compare our results with those from the 16 subgroup IV stations, also from the Fladen Ground. These 16 stations had a range of species numbers of 27 to 80 and of total abundance of 1760 to 5930 organisms $\mathrm{m}^{-2}$. McIntyre's (1961) study of 20 van Veen grab samples $\left(0.1 \mathrm{~m}^{2}\right)$ from the Fladen Ground contained 89 species (including thyasirids but excluding foraminifera) and 2476 ind. $\mathrm{m}^{-2}$ The biomass at the 16 stations of Eleftheriou \& Basford was 0.7 to $9.7 \mathrm{~g}$ estimated dry weight $\mathrm{m}^{-2}$, with a mean of 3.1 , and for McIntyre's study it was ca $6.6 \mathrm{~g} \mathrm{~m}^{-2}$ (assuming that dry weight was $80 \%$ of formalin-preserved wet weight). This compares with estimated values of 0.3 to $3.9 \mathrm{~g}$ for our samples from the side of the pockmark. The biomass figures in all the individual samples was heavily influenced by single large animals. At present we cannot be certain of the extent to which the differences observed between numbers of species and numbers of individuals reflect true 'between-year' differences or seasonal variation or both.

The meiofauna in this pockmark was dominated by nematodes, as previously found by McIntyre (1964) for samples from the Fladen Ground in $146 \mathrm{~m}$ depth at $58^{\circ} 20^{\prime} \mathrm{N}, 05^{\circ} 30^{\prime} \mathrm{E}$. In the samples from the side of the pockmark the density of all nematodes was $533 \times 10^{3}$ $\mathrm{m}^{-2}$ and $719 \times 10^{3} \mathrm{~m}^{-2}$ compared to between 755 and $3020 \times 10^{3}$, with a mean of $1845 \times 10^{3} \mathrm{~m}^{-2}$, in McIntyre's samples. As with the macrofauna there is an impoverished population at the base of the pockmark. We suggest that fluid leakage from the pockmark is sufficient to remove the silty surface sediments and prevent the establishment of a stable community at the base. Further surveys of pockmarks and their surrounding sediments are needed to verify this.

The dominant nematode found in the present investigation was a species of Astomonema. The species from the pockmark closely resembles $A$. jenneri (Ott et al. 1982) in general form, in lack of mouth and gut, and in the appearance of its endosymbiotic bacteria. (This nematode will be described in a separate publication by $M$. Austen \& R. M. Warwick, and its symbiotic bacteria will be described by E. C. Southward.) A. jenneri was found in reducing muddy intertidal sandflats, in North Carolina, USA, living in the outer part of polychaete tubes. Other mouthless species of Astomonema have been described from mud at 310 to $650 \mathrm{~m}$ in the Gulf of Lion, France (Vitiello 1971), at $19 \mathrm{~m}$ depth in fine sand in the Bay of Morlaix, north Brittany, France (Boucher \& Helléouët 1977), and in a sandy-silt bottom at $40 \mathrm{~m}$ depth in the northern Adriatic (Vidakovic \& Boucher 1987). Gutless nematodes have not previously been described from the vicinity of hydrocarbon seeps and this pockmark is the only habitat so far described where free-living nematodes with endosymbiotic bacteria are the dominant species in the meiofauna.

We do not have direct evidence for the type of bacteria present in these nematodes. The bacteria, when examined by TEM (E. C. Southward pers. comm.), most resemble the presumed sulphur-oxidising endosymbiotic bacteria found in gutless oligochaetes (Giere \& Langheld 1987). They do not have internal membrane systems typical of either type I or type II methanotrophs and the methane content of the sediment cores in which they were found does not suggest that this would be a suitable energy source. Since thyasirid bivalves known to have symbiotic sulphur-oxidising bacteria live in the sediments of the pockmark it is likely that these associations between nematodes and prokaryotes use the same resource. The depth distribution of Astomonema sp. in $\mathrm{R} 1$ indicated that it had a maximum abundance at a depth of 5 to $8 \mathrm{~cm}$, coinciding with a maximum concentration of elemental sulphur. This depth was just above a region of high sulphide concentration, and the zone of maximum sulphate reduction rate, and below the region of aerobic methane oxidation. If Astomonema does depend for its nutrition on symbiotic sulphur-oxidising bacteria this is precisely the region of the sediment in which it would be 
expected to occur, at the interface between the oxidised and reduced zones. Ott \& Novak (1989) have demonstrated a similar sediment distribution for the stilbonematine nematodes which have guts but appear to feed on the ectosymbiotic bacteria growing on their cuticle. These ectosymbionts are also presumed to be sulphur oxidisers.

Tissues from animals collected in the trawls across the pockmark gave $\delta^{13} \mathrm{C}$ values mostly in the range expected for benthos feeding heterotrophically on plankton-derived organic carbon $(-16$ to $-20 \%)$. Much greater ${ }^{13} \mathrm{C}$ depletions would have been expected if there was an extensive food web based on free-living methanotrophic bacteria oxidising methane with a depletion of $-71 \%$. There were a few exceptions to the above values: an Echinocardium flavescens with a $\delta^{13} \mathrm{C}$ of $-22.9 \%, 2$ Pennatula phosphorea with values of -21 and $-22.8 \%$, and Thyasira sarsi. The 3 specimens of this thyasirid analysed showed depletions between -31 and $-35 \%$ and shell $\delta^{13} \mathrm{C}$ values of -4.8 and $-5.1 \%$. Such values for $T$. sarsi fall between those observed for animals found in organic-enriched fjord muds and a methane-seep site in the Skagerrak (Spiro et al. 1986, Schmaljohann et al. 1990).

The results from these first cruises to study the biology of a North Sea pockmark with an active methane seep suggest that the methane carbon is not contributing to the carbon of the surrounding infauna on a significant scale. There is little evidence that isotopically light methane carbon is making a significant contribution to the tissue carbon of the benthic invertebrates around the pockmark. The $\delta^{13} \mathrm{C}$ values of the sedimentary organic matter and carbonate from 2 cores from the pockmark sides are in the expected range for normal marine sediments and show no evidence for organic matter formed by methanotrophy or chemoautotrophy nor for the presence of authigenic carbonate. This is additional evidence for the dominance of photosynthetic carbon in this ecosystem. Any significant contribution of methane carbon to the food chain is likely to be confined to locations very close to the actual gas seep where the carbonate-cemented sandstone occurs (Hovland \& Judd 1988): more precise sampling will be needed to show this. This conclusion contrasts with the suggestion by Hovland \& Judd (1988) and Hovland \& Thomsen (1989) that the fauna around North Sea pockmarks and methane seeps is dependent on a hydrocarbon-based food chain. It is possible that the greater density of visible fauna observed on video records from a variety of different sites is due partly to the hard substrate (carbonate cement slabs and shells), providing a habitat for anthozoans and bryozoans, and partly to resuspension of the bottom sediments by escaping gas. The resuspension could provide additional food for filter feeders. Small fish would be more abundant due to the shelter provided by the rocks and shell debris.

Acknowledgements. We thank Dr R. M. Warwick for help and advice on nematode identification, Keith Ryan for the X-ray microanalysis, Llynne McCarthy for assistance at sea and with the analytical work, Greg Fullarton for assistance on the 'Resolution', Alastair Macintosh for assistance on the 'Scotia' and Javier Alcala-Herrera and Karen Bigley for help with the stable isotope measurements. This study was funded in part by the Institute of Petroleum and by the UK Department of the Environment as a contribution to its co-ordinated programme of research on the North Sea. R.B. and M.C.K. also received support from the Texas A \& M University Sea Grant Programme.

\section{LITERATURE CITED}

Austen, M. C., Warwick, R. M. (1989). Comparison of univariate and multivariate aspects of estuarine meiobenthic community structure. Estuar. coast. Shelf Sci. 29: 23-42

Boucher, G. Helléouët, M. N. (1977). Nématodes des sables fins infralittoraux de la Pierre Noire (Manche occidentale). III. Araeolaimida et Monohysterida. Bull. Mus. natn. Hist. nat. Paris, $3^{e}$ sér. 427: 85-122

Cline, J. D. (1969). Spectrophotometric determination of hydrogen sulphide in natural waters. Limnol. Oceanogr. 14: $141-152$

Dando, P. R., Southward, A. J. (1986). Chemoautotrophy in bivalve molluscs of the genus Thyasira. J. mar. biol. Ass. U.K. 66: 915-929

Dando, P. R., Southward, A. J., Southward, E. C., Terwilliger, N. B., Terwilliger, R. C. (1985). Sulphur-oxidising bacteria and haemoglobin in gills of the bivalve mollusc Myrtea spinifera. Mar. Ecol. Prog. Ser. 23: 85-98

Dando, P. R., Southward, A. J., Southward, E. C. (1986). Chemoautotrophic symbionts in the gills of the bivalve mollusc Lucinoma borealis and the sediment chemistry of its habitat. Proc. R. Soc. Lond. B 227: 227-247

Davis, P. H., Spies, R. B. (1980). Infaunal benthos of a natural petroleum seep: a study of community structure. Mar. Biol. 59: $31-41$

Eleftheriou, A., Basford, D. J. (1989). The macrobenthic infauna of the northern North Sea. J. mar. biol. Ass. U. K., 69: $123-143$

Giere, O, Langheld, C. (1987). Structural organisation, transfer and biological fate of endosymbiotic bacteria in gutless oligochaetes. Mar. Biol. 93: 641-650

Hartley, J. P. (1984). The benthic ecology of the Forties oilfield (North Sea). J. exp. mar Biol. Ecol. 80: 161-195

Hovland, M., Irvin, H. (1989). Habitat of methanogenic carbonate cemented sediments in the North Sea. Abstracts of the bacterial gas conference. Milan, September 1989

Hovland, M. Judd, A. G. (1988). Seabed pockmarks and seepages. Graham and Trotman Ltd, London

Hovland, M., Sommerville, J. M. (1985). Characteristics of two natural gas seepages in the North Sea. Mar Petroleum Geol. 2: 319-326

Hovland, M., Thomsen, E. (1989). Hydrocarbon-based communities in the North Sea? Sarsia 74: 29-42

Ivanov, M. V., Lein, A. Yu., Reeburgh, W S., Skyring. G. W (1989). Interaction of sulphur and carbon cycles in marine sediments. In: Brimblecombe, P., Lein, A. Yu. (ed.) Evolution of the global biogeochemical sulphur cycle SCOPE 39. John Wiley \& Sons, Chichester, p. 125-179 
Iversen, N., Jørgensen, B. B. (1985). Anaerobic methane oxidation rates at the sulfate-methane transition in marine sediments from Kattegat and Skagerrak (Denmark). Limnol. Oceanogr 30: 944-955

Jansen, J. H. F. (1976). Late Pleistocene and Holocene history of the northern North Sea, based on acoustic reflection records. Neth. J. Sea Res. 10: 1-43

Jensen, S., Spärck, R. (1934). Danmarks fauna. Bløddyr II Saltvandsmuslinger. G. E. C. Gads Forlag, Copenhagen

Jonasson, A., Olausson, E. (1966). New devices for sediment sampling. Mar. Geol. 4: 365-372

Jørgensen, B. B. (1978). A comparison of methods for the quantification of bacterial sulfate reduction in coastal marine sediments. Geomicrobiol. J. 1: 11-27

Jørgensen, B. B. (1989). Sulfate reduction in marine sediments from the Baltic Sea-North sea transition. Ophelia 31: 1-15

Josefson, A. B. (1985). Distribution of diversity and functional groups of marine benthic infauna in the Skagerrak (eastern North Sea) - can larval availability affect diversity? Sarsia 70: 229-249

Kennicutt, M. C., Brooks, J. M., Bidigare, R. R., McDonaid S. J., Adksion, D. L., Macko, S. A. (1989). An upper slope 'cold' seep community; Northern California. Limnol. Oceanogr 34: 635-640

Kennicutt, M. C., Brooks, J. M., Bidigare, R. R., Fay, R. R. Wade, T L., McDonald, S. J. (1985). Vent-type taxa in a hydrocarbon seep region on the Louisiana slope. Nature Lond. 317: 351-352

Lauren, D. R., Watkinson, J. H. (1985). Elemental sulphur analysis using high-performance liquid chromatography on $10-\mu \mathrm{m}$ rigid polymer particles. J. Chromatog. 348: $317-320$

Long, D. (1986). Seabed sediments, Fladen Sheet $58^{\circ} \mathrm{N}-00^{\circ}$ British Geological Survey, Edinburgh

Ott, J. A., Novak, R. (1989). Living at an interface: meiofauna at the oxygen/sulfide boundary of marine sediments. In Ryland, J. S., Tyler, P. A. (eds.) Proc. 23rd Eur. Mar. Biol Symp. Reproduction, genetics and distribution of marine organisms. Olsen \& Olsen, Fredensborg, p. 415-421

Ott, J., Rieger, G., Rieger, R., Enderes, F. (1982). New mouthless interstitial worms from the sulfide system: symbiosis with prokaryotes. P.S.Z.N. I: Mar. Ecol. 3: 313-333

McIntyre, A. D. (1961). Quantitative differences in the fauna of

This article was presented by Dr A. J. Southward, Plymouth, UK boreal mud associations. J. mar. biol. Ass. U. K. 41 : 599-616

Mcintyre, A. D. (1964). Meiobenthos of sub-littoral muds. J. mar, biol. Ass. U. K. 44: 665-674

Paull, C. K., Jull, A. J. T., Toolin, L. J., Linick, T (1985). Stable isotope evidence for chemoautotrophy in an abyssal seep community. Nature, Lond. 317: 709-711

Petersen, G. H. (1977). The density, biomass and origin of the bivalves of the Central North Sea. Meddr. Danm. Fisk-og Havunders. N. S. 7: 221-273

Schmaljohann, R., Faber, E., Whiticar, M. J., Dando, P. R. (1990). Co-existence of methane- and sulphur-based endosymbioses between bacteria and invertebrates at a site in the Skagerrak. Mar. Ecol. Prog. Ser. 61: 119-124

Schmaljohann, R., Flügel, H. (1987). Methane oxidising bacteria in Pogonophora. Sarsia 72: 91-98

Southward, E. C. (1986). Gill symbionts in thyasirids and other bivalve molluscs. J. mar. biol. Ass. U. K. 66: 889-914

Sørensen, J., Jørgensen, B. B. (1987). Early diagenesis of sediments from Danish coastal waters: microbial activity and Mn-Fe-S geochemistry. Geochim. Cosmochim. Acta 51. $1583-1590$

Spies, R. B., Davis, P. H., Stuermer, D. H. (1980). Ecology of a submarine petroleum seep off the California coast. In Geyer, R. A. (ed.) Marine environmental pollution, Vol. 1, Hydrocarbons. Elsevier Scientific Publishing Co., Amsterdam, p. 229-263

Spiro, B., Greenwood, P. B., Southward, A. J., Dando, P. R. (1986). ${ }^{13} \mathrm{C} /{ }^{12} \mathrm{C}$ ratios in marine invertebrates from reducing sediments: confirmation of nutritional importance of chemoautotrophic endosymbiotic bacteria. Mar. Ecol. Prog. Ser. 28: 233-240

Vidakovic, J., Boucher, G. (1987). Gutless nematodes of the genus Astomonema Ott et al., 1982. Cah. Biol. mar. 28: 11 1120

Vitiello, P. (1971). Nématodes libres marins des vases profondes du Golfe du Lion. III. Monhysterida, Araeolaimida, Desmodorida. Tethys 2: 647-690.

Zhabina, N. N., Volkov, I. I. (1978). A method of determination of various sulphur compounds in sea sediments and rocks. In: Krumbein, W. E. (ed.) Environmental biogeochemistry and geomicrobiology, Vol. 3, Methods, metals and assessment. Ann Arbor Science Publishers, Ann Arbor, p. $735-746$

Manuscript first received. July 3, 1990

Revised version accepted: November 6, 1990 